\title{
Determination of the Cytomegalovirus (CMV) infection Role with the Disturbances of Immunoglobulin E (IgE) and Interleukin-33 (IL-33) Concentrations in the Pathogenesis of Asthma and Atherosclerosis in a Sample of Iraqi Patients
}

\author{
Jasim Mohammed Muhsin ${ }^{1 *}$ (D), Sura O. Yousif², Ameer M. Hadi ${ }^{3}$ and Ahmed \\ Rahman Rawdhan ${ }^{4}$
}

${ }^{1}$ Middle Technical University, Health and Medical Technology College, Baghdad, Iraq. ${ }^{2}$ Technical Institute, Suwaira, Middle Technical University, Wasit, Iraq. ${ }^{3}$ University of Babylon, DNA Research Center, Babylon, Iraq. ${ }^{4}$ Shiekh Zayed Hospital, Baghdad, Iraq.

\begin{abstract}
Subsequently, the early reactivation or old human cytomegalovirus (HCMV) infection may be interfere with IgE and interleukin-33 (IL-33) levels disturbances throughout the life intervals and act as synergistic factors to play a significant role in the pathogenesis of various diseases; like asthma or coronary heart diseases (CHD). The main subject of the current study was to determine the role of CMV infection onto IgE levels and IL-33 disturbances in the pathogenesis of asthma and atherosclerosis as a case-control study. A total of 175 participants were with a mean age of $38.17 \pm 7.51$ years [age range: 26-52] years, which were distributed as patients with atherosclerosis $(n=50)$ and asthmatic patients $(n=50)$ as the cases of our study and 75 healthy subjects as a control group. Both groups of asthmatic and atherosclerosis patients show a significant association with the seropositivity of CMV-IgG which was detected in 33 (18.9\%) and 30 (17.1\%). While, CMV-PP65 Ag which was detected in $26(14.9 \%)$ and $28(16.0 \%)$ respectively $(P<0.0001)$. High level of abnormal IL-33 was detected in $36(20.6 \%)$ with 45 (25.7\%) of abnormal IgE was determined in patients with asthma followed by 26 (14.9\%) and 44 (25.1\%) for abnormal levels of IL-33 and IgE respectively in patients with atherosclerosis. Furthermore, there was a positive significant association between the seropositivity of CMV-IgG and CMV-PP65 Ag with abnormal IgE and IL-33 levels in the pathogenesis of asthma and atherosclerosis $(P<0.0001)$, and impact of our study support the hypothesis that previous cytomegalovirus infection or early reactivation with unregulated IL-33 expression or high IgE level play a significant role in the pathogenesis of coronary heart diseases and asthma.
\end{abstract}

Keywords: Allergy, Coronary heart diseases (CHD), Cytomegalovirus (CMV), Interleukin (IL-33), IgE.

*Correspondence: Jasim.muhsin99@gmail.com; Phone: 009647735414764

(Received: 04 April 2019; accepted: 20 May 2019)

Citation: Jasim Mohammed Muhsin, Sura O. Yousif and Ahmed Rahman Rawdhan, Determination of the Cytomegalovirus (CMV) infection Role with the Disturbances of Immunoglobulin E (IgE) and Interleukin-33 (IL-33) Concentrations in the Pathogenesis of Asthma and Atherosclerosis in a Sample of Iraqi Patients, J Pure Appl Microbiol., 2019; 13(2): 1003-1010. doi: 10.22207/ JPAM.13.2.37

C The Author(s) 2019. Open Access. This article is distributed under the terms of the Creative Commons Attribution 4.0 International License which permits unrestricted use, sharing, distribution, and reproduction in any medium, provided you give appropriate credit to the original author(s) and the source, provide a link to the Creative Commons license, and indicate if changes were made. 


\section{INTRODUCTION}

Human cytomegalovirus (HCMV) or human herpesviruses 5 , (HHV-5) is a genus of DNA virus of Herpesviridae family and Betaherpesvirinae subfamily, with primary asymptomatic infection, a virus with latency cycle, also it's one of the causative agents of infectious mono-nucleosis ${ }^{1}$. The primary infection of $\mathrm{CMV}$ characterized by the presence of IgM immuno-globulins or another indicator of active infection more than CMV IgM antibody which is phosphoprotein 65 (pp65); the most copious constituent of the virion tegument of human cytomegalovirus (HCMV) protein. The positive CMV pp65 antigen in patient serum appeared on average of nine days earlier of serologic evidence of primary active infection. Therefore, detection of CMV pp65 antigens consider earlier and has been a valued tool for detection of early disease progression (active CMV disease $)^{3}$. Later, the existence of immunoglobulin $\mathrm{G}$ (IgG) antibodies for a lifetime (seropositivity) its evidence of previous (old CMV infection)2.

A study revealed the prevalence of CMV DNA increasing in the blood of asthmatic patients throughout the lifetime; proposes that disorder associated with latent CMV infection and may contribute to asthma pathogenesis ${ }^{7}$. Furthermore, some studies linked between CMV IgG sero-positivity or CMV reactivations with cardio-vascular disease progression that assumed to increase mortality risk ${ }^{4}$. Other herpesviruses or papilloma viruses maybe also of importance with the heart diseases interferences, but the possibility of interaction has been explored to a limited extent ${ }^{5-6}$.

Asthma and coronary heart disorders are represented by excessive inflammatory dysregulation processes which occur in developing countries. They lead to serious health problems and affect negatively the quality of life. Studies suggested an association between allergy and an increased risk of coronary heart disease (CHD), resulting by over synthesis of pro-inflammatory cytokines in allergic diseases and disturbances of immune reactions, which has been interfered in the pathogenesis of atherosclerosis mechanisms ${ }^{8}$.

The aim of this article, to explore CMV infection by; whether seropositivity for CMV IgG antibody (past infection) or CMV pp65 antigens (recent infection) are related to asthma and coronary heart diseases among participants in case-control study and whether the proinflammatory and immune reaction have any association with the pathogenesis of these disorders.

\section{MATERIALS AND METHODS Participants}

A (case-control) study was established from the first of August till to the $30^{\text {th }}$ of September (2018), with 175 serum samples of adult participants (aged 26-52), which distributed into (75) a healthy subjects as controls and (50) individuals had been with asthma which collected from Specialized Center of Allergy and Asthma, Baghdad. Furthermore, another fifteen individuals who admitted to Ibn al-Bitar for Cardiac Surgery Hospital, Baghdad, for coronary heart diseases such as; atherosclerosis. All cases diagnosed with specialized physician and some laboratory tests. The study protocols approved by the local Ethics Committee.

Measurement of CMV-IgG, CMV-PP65 Ag, IgE and IL-33 serum levels

The commercial ELISA of CMV/IgG (Diagnostic Automation/ Cortez Diagnostics, Inc., USA / HCMV-IgG) was used for estimation of CMV IgG antibodies. All analysis steps were performed according to the instructions of the manufacturer, (Cut-off Index = 1.0).

(MyBioSource Inc., USA / CMV-PP65 Ag) Commercial (ELISA) kit was used to detect CMVPP65 Antigens in serum samples. (Cut-off Index $\geq 1.0$ ).

(Diagnostic Automation / Cortez Diagnostics, Inc., USA / IgE) commercial ELISA IgE kit was used to detect the IgE levels according to the manual instructions (Range: $0-800 \mathrm{IU} / \mathrm{mL}$; sensitivity: $5 \mathrm{IU} / \mathrm{mL}$ ).

(MyBioSource Inc., USA / IL-33) Commercial (ELISA) kit was applied to detect IL-33 serum concentration levels. The interleukin assay was conducted using the instruction manual which is recommended by the manufacturers (standard range: $15.6-1000 \mathrm{pg} / \mathrm{ml}$; sensitivity: $<9.375 \mathrm{pg} /$ $\mathrm{ml}$ ).

\section{Statistical analysis}

All statistical analysis was accomplished with (SPSS, Inc., Chicago, IL USA, ver.19.0). The results of quantitative data were expressed as 
mean \pm standard deviation (mean \pm SD) for all continuous variables and compared with oneway ANOVA and independent t-Test. Pearson's correlation was applied to examine the relation between dependent and independent variables. Furthermore, qualitative data were compared with the chi-square test. $p$-value $<0.05$ was considered statistically significant.

\section{RESULTS}

In this study, $50(28.6 \%)$ patients with allergic disorders 17 (9.7\%) males and 33 (18.9\%) females, with a mean age of $37 \pm 7.4$ years [age range: $24-26]$ and $50(28.6 \%)$ patients with cardiovascular diseases 35 (20.0\%) males and $15(8.6 \%)$ females, with mean age $39 \pm 7.2$ years [age range of 26-52]. In addition to, 75 (42.9\%) participants as healthy subjects $49(28.0 \%)$ males and 26 (14.9\%) females, with a mean age of 37.3 \pm 7.6 years [age range: $26-49$ ] were scanned.

Table (1) explored the demographic characteristics of all participants, $44(25.1 \%)$ of allergic disorders patients had abnormal (High) IgE levels with abnormal IL-33 expression in 36
$36(20.6 \%), 33(18.9 \%)$ of them had been with a positive CMV-IgG. While, cardiovascular diseases patients $44(25.1 \%)$ had been with a high level of IgE and 26 (14.9\%) expressed abnormal IL-33 concentration with the seropositivity of CMV-IgG it was in 30 (17.1\%) of them, with highly significant differences $(P<0.001)$.

The mean comparisons of serological markers of (CMV-IgG, IgE and IL-33) concentration according to the study groups in the table (2) which shows high significant differences between variables $(P<0.001)$. High levels of IL-33 were detected in allergic disorders patients compared with controls (584.6 \pm 298.9 vs. $184.1 \pm 95.0$ ). Moreover, the patients with CVD had a high level of IgE than healthy control $(145.6 \pm 43.8$ vs. 46.4 \pm 19.0$)$.

The correlation between CMV-IgG Seropositivity with IgE and IL-33 exposed high significantly positive associations between them $(P=0.001, R=0.48)$ and $(P=0.001, R=0.47)$ respectively. Furthermore, with age showed that a large proportion had been with old infection had significantly higher levels of CMV-IgG $(P=0.15, R$

Table 1. Baseline data of study population characteristics

\begin{tabular}{|c|c|c|c|c|c|}
\hline $\begin{array}{c}\text { Characteristics } \\
\mathrm{N}(\%)\end{array}$ & & $\begin{array}{l}\text { Control } \\
\mathrm{N}=75 \\
(42.9 \%)\end{array}$ & $\begin{array}{l}\text { asthmatics } \\
\mathrm{N}=50 \\
(28.6 \%)\end{array}$ & $\begin{array}{l}{ }^{*} \mathrm{CHD} \\
\mathrm{N}=50 \\
(28.6 \%)\end{array}$ & $\begin{array}{l}p . \\
\text { value }\end{array}$ \\
\hline \multirow{2}{*}{ Genders } & Male & 49 (28.0\%) & 17 (9.7\%) & 35 (20.0\%) & $<0.001$ \\
\hline & Female & 26 (14.9\%) & 33 (18.9\%) & $15(8.6 \%)$ & \\
\hline \multirow[t]{2}{*}{ Age (Years) } & $(26-40)$ & 31 (17.7\%) & 20 (11.4\%) & $14(8.0 \%)$ & 0.28 \\
\hline & $\geq 41$ & 44 (25.1\%) & 30 (17.1\%) & $36(20.6 \%)$ & \\
\hline \multirow[t]{2}{*}{ Diseases History } & Yes & $0(0.0 \%)$ & 30 (17.1\%) & 37 (21.1\%) & $<0.001$ \\
\hline & No & 75 (42.9\%) & 20 (11.4\%) & $13(7.4 \%)$ & \\
\hline \multirow[t]{2}{*}{ Smoking status } & Smoker & $5(2.9 \%)$ & 40 (22.9\%) & $32(18.3 \%)$ & $<0.001$ \\
\hline & Non-smoker & 70 (40.0\%) & $10(5.7 \%)$ & $18(10.3 \%)$ & \\
\hline \multirow[t]{2}{*}{${ }^{*} \mathrm{BMI}\left(\mathrm{kg} / \mathrm{m}^{2}\right)$} & Normal weight & 75 (42.9\%) & $3(1.7 \%)$ & $2(1.1 \%)$ & $<0.001$ \\
\hline & Over weight & $0(0.0 \%)$ & 47 (26.9\%) & $48(27.4 \%)$ & \\
\hline \multirow[t]{2}{*}{ CMV-IgG } & Negative & 65 (37.1\%) & $17(9.7 \%)$ & 20 (11.4\%) & $<0.001$ \\
\hline & Positive & $10(5.7 \%)$ & 33 (18.9\%) & $30(17.1 \%)$ & \\
\hline \multirow[t]{2}{*}{ *CMV-PP65 Ag } & Negative & 67 (38.3\%) & $24(13.7 \%)$ & $22(12.6 \%)$ & $<0.001$ \\
\hline & Positive & $8(4.6 \%)$ & 26 (14.9\%) & $28(16.0 \%)$ & \\
\hline \multirow[t]{2}{*}{ *IgE Levels } & Normal & 75 (42.9\%) & $5(2.9 \%)$ & $6(3.4 \%)$ & $<0.001$ \\
\hline & Abnormal & $0(0.0 \%)$ & 45 (25.7\%) & $44(25.1 \%)$ & \\
\hline \multirow[t]{2}{*}{ *IL-33 Levels } & Normal & 71 (40.6\%) & $14(8.0 \%)$ & 24 (13.7\%) & $<0.001$ \\
\hline & Abnormal & $4(2.3 \%)$ & $36(20.6 \%)$ & 26 (14.9\%) & \\
\hline
\end{tabular}

Chi-square test was conducted to test the association between demographic characters and study groups* BMI $\left(\mathrm{kg} / \mathrm{m}^{2}\right)=\mathrm{Body}$ mass index (Kilogram/meters squares) ${ }^{*} \mathrm{CHD}=$ Coronary heart diseases $*$ CMV-PP65 Ag $=$ phosphoprotein 65 antigens $*$ IgE $=$ Immunoglobulin $\mathrm{E}^{*} \mathrm{IL}-33=$ Interleukin 33 
Muhsin et al. J Pure Appl Microbiol, 13(2), 1003-1010 | June 2019 | DOI 10.22207/JPAM.13.2.37

Table 2. Comparison association of the mean levels among studied serological markers according to the study groups

\begin{tabular}{llllll}
\hline $\begin{array}{l}\text { Groups } \\
\text { (mean } \pm \text { SD) }\end{array}$ & CMV-IgG & $\begin{array}{l}\text { CMV-PP65 } \\
\text { Ag }\end{array}$ & IgE Levels & $\begin{array}{l}\text { IL-33 } \\
\text { Levels }\end{array}$ & p.value \\
\hline Asthmatics $(n=50)$ & $1.54 \pm 0.88$ & $1.06 \pm 0.84$ & $145.5 \pm 37.2$ & $584.6 \pm 298.9$ & $<0.001$ \\
CHD $(n=50)$ & $1.49 \pm 0.90$ & $1.23 \pm 0.87$ & $145.6 \pm 43.8$ & $438.5 \pm 289.4$ & $<0.001$ \\
Control $(n=57)$ & $0.5 \pm 0.4$ & $0.52 \pm 0.46$ & $46.4 \pm 19.0$ & $184.1 \pm 95.0$ & $<0.001$ \\
Total $(n=175)$ & $1.11 \pm 0.87$ & $0.88 \pm 0.78$ & $103.1 \pm 59.2$ & $371.2 \pm 286$ & $<0.001$ \\
\hline
\end{tabular}

One-way ANOVA test was conducted to test the mean levels comparison serological markers and study groups

$=0.01$ ) and concerning to the $\mathrm{BMI}$, reveled high significant positive association with abnormal; weight $(P=0.001, R=0.49)$ and significant negative association ( $P=0.001, R=-0.26)$ with smoking status, but there was no association with genders and CMV-IgG seropositivity as represented in table (3).

Furthermore, there was a significantly positive associations between CMV-pp65 Ag with IgE and IL-33 exposed high them $(P=0.001$, $R=0.36)$ and $(P=0.001, R=0.26)$ respectively. Besides, there was positive significant relation with age and $\mathrm{BMI}(P=0.01, R=0.16, P=0.001$, $R=0.32)$ and significant negative association $(P=$ $0.02, R=-0.15$ ) with smoking status, table (4).

Table (5) demonstrate the comparison association of the mean level of IL-33 concentration, it was with the high significant difference among all demographic characteristics $(P<0.001)$ except with age it was a non-significant difference $(P=$ 0.95). The level of IgE and CMV-IgG did not show significant differences with age and genders but both of them show a higher significant difference with the diseases history, smoking status and BMI $(P<0.001)$.

\section{Recommendations}

The current results may not be generalized to all diseases in the selected sample so it is useful to review a large sample size with other molecular markers in order to understand the biology of this issue. In addition to, estimate SST2 level concentration as a decoy IL-33 receptor.

\section{DISCUSSION}

The distinctiveness of the resent study was to estimate the interaction role of four serological markers (CMV-IgG, CMV-pp65, IgE and IL-33) in the pathogenesis of two inflammatory
Table 3. Correlation of CMV-IgG Seropositivity with overexpression of interleukin-33, total IgE levels, and other demographic characters

\begin{tabular}{lcc}
\hline $\begin{array}{l}\text { Serological } \\
\text { Markers }\end{array}$ & $\begin{array}{c}\text { Pearson } \\
\text { Correlation }(r)\end{array}$ & $\begin{array}{c}p . \\
\text { value }\end{array}$ \\
\hline IgE Levels & 0.48 & 0.001 \\
IL-33 Levels & 0.47 & 0.001 \\
Age (Years) & 0.15 & 0.01 \\
Genders & 0.08 & 0.12 \\
BMI (kg/m ${ }^{2}$ ) & 0.49 & 0.001 \\
Smoking status & -0.26 & 0.001
\end{tabular}

Pearson Correlation test was applied to test the correlation of $\mathrm{CMV}$-lgG with serological markers and demographic characteristics

Table 4. Correlation of CMV-PP65 Ag with overexpression of interleukin-33, total IgE levels, and other demographic characters

\begin{tabular}{lcc}
\hline $\begin{array}{l}\text { Serological } \\
\text { Markers }\end{array}$ & $\begin{array}{c}\text { Pearson } \\
\text { Correlation }(r)\end{array}$ & $\begin{array}{c}p . \\
\text { value }\end{array}$ \\
\hline IgE Levels & 0.36 & 0.001 \\
IL-33 Levels & 0.26 & 0.001 \\
Age (Years) & 0.16 & 0.01 \\
Genders & -0.35 & 0.32 \\
BMI (kg/m $\left.{ }^{2}\right)$ & 0.32 & 0.001 \\
Smoking status & -0.15 & 0.02 \\
\hline
\end{tabular}

Pearson Correlation test was applied to test the correlation of CMV-PP65 Ag with serological markers and demographic characteristics

disorders which are; asthma and athero-sclerosis. However, this study has limitations, it's significant to interpret the recent outcomes in a larger sample size with multiple genetic markers for better understanding the biology of these disorders with further immunological and virologic markers. 
Table 5. Comparison association of the mean levels of CMV-IgG, CMV-PP65 Ag, total lgE and interleukin-33 level in baseline data of study participants

\begin{tabular}{|c|c|c|c|c|c|c|}
\hline \multirow[t]{2}{*}{ Characteristics } & \multirow[t]{2}{*}{$\mathrm{N}$} & \multicolumn{3}{|c|}{ Serological Markers (mean \pm SD) } & \multirow[b]{2}{*}{$\lg E$} & \multirow[b]{2}{*}{ IL-33 } \\
\hline & & (\%) & $\begin{array}{l}\text { CMV- } \\
\text { lgG }\end{array}$ & $\begin{array}{l}\text { CMV- } \\
\text { PP65 Ag }\end{array}$ & & \\
\hline \multirow[t]{3}{*}{ Genders } & Male & $101(75.7 \%)$ & $1.0 \pm 0.87$ & $0.90 \pm 0.78$ & $97.2 \pm 60.2$ & $297.67 \pm 230.50$ \\
\hline & Female & $74(42.3 \%)$ & $1.2 \pm 0.86$ & $0.84 \pm 0.77$ & $111.17 \pm 57.2$ & $471.66 \pm 324.22$ \\
\hline & p.value & 0.25 & 0.64 & 0.12 & $<0.001$ & \\
\hline \multirow[t]{3}{*}{ Age (Years) } & $(26-40)$ & $65(37.1 \%)$ & $0.95 \pm 0.85$ & $0.75 \pm 0.77$ & $98.7 \pm-61.2$ & $372.9 \pm 287.09$ \\
\hline & $\geq 41$ & $110(62.9 \%)$ & $1.12 \pm 0.87$ & $0.95 \pm 0.76$ & $105.7 \pm 58.07$ & $370.2 \pm 287.42$ \\
\hline & p.value & 0.06 & 0.10 & 0.45 & 0.95 & \\
\hline Diseases & Yes & $67(38.3 \%)$ & $1.45 \pm 0.93$ & $1.09 \pm 0.86$ & $136.6 \pm 41.8$ & $491.3 \pm 320.9$ \\
\hline \multirow[t]{2}{*}{ History } & No & $108(61.7 \%)$ & $0.90 \pm 0.76$ & $0.74 \pm 0.69$ & $82.3 \pm 58.9$ & $296.7 \pm 235.1$ \\
\hline & p.value & $<0.001$ & 0.004 & $<0.001$ & $<0.001$ & \\
\hline \multirow{3}{*}{$\begin{array}{l}\text { Smoking } \\
\text { status }\end{array}$} & Smoker & 77 (44.0\%) & $1.38 \pm 0.90$ & $1.01 \pm 0.83$ & $141.7 \pm 47.8$ & $509.9 \pm 309.2$ \\
\hline & Non-smoker & $98(56.0 \%)$ & $0.9 \pm 0.79$ & $0.77 \pm 0.72$ & $72.7 \pm 48.7$ & $262.2 \pm 212.1$ \\
\hline & p.value & $<0.001$ & 0.04 & $<0.001$ & $<0.001$ & \\
\hline $\mathrm{BMI}$ & Normal weight & $80(45.7 \%)$ & $0.62 \pm 0.51$ & $0.56 \pm 0.52$ & $52.4 \pm 30.0$ & $198.5 \pm 132.4$ \\
\hline \multirow[t]{2}{*}{$\left(\mathrm{kg} / \mathrm{m}^{2}\right)$} & Overweight & $95(54.3 \%)$ & $1.53 \pm 0.89$ & $1.15 \pm 0.85$ & $145.8 \pm 41.0$ & $516.6 \pm 300.6$ \\
\hline & p.value & $<0.001$ & $<0.001$ & $<0.001$ & $<0.001$ & \\
\hline
\end{tabular}

Independent $t$-Test test was applied to test the mean comparison of serological markers according to demographic characteristics, data were presented as mean \pm SD.

Cytomegalovirus has a variable tissue tropism by its ability to infect different organs and interfere with many disorders such as; atherosclerosis, hypertensive blood pressure, cervical cancer and autoimmune diseases ${ }^{9-12}$.

A study verified that the patient had been established hypersensitivity syndrome related to $\mathrm{CMV}$ reactivation by the increasing CMV-IgG accompanied by low CMV replication level was predominant among asthmatic participants ${ }^{13}$. Another study concluded that HCMV infection is related to asthma and may play a role in the pathogenesis of asthmatic inflammation by the detection of HCMV DNA in about $10.7 \%$ of the asthmatic patients ${ }^{14}$.

Otherwise, a study was found CMV DNA increased by age with double IgE count to be connected with a risk of asthma traits comparing to controls. Nevertheless, herpesviruses infection has been measured to have a probable influence on the progression of the atopic disorder, so it cannot be omitted CMV chronic infection or reactivation that may have a fundamental influence on the traits of asthma progressing ${ }^{15}$.

In addition, the relation of IL-33 with asthma and allergies is still uncertain. However, only a few studies have been conducted in humans and the impact of IL-33 has been proved in some allergic diseases such as; allergic rhinitis ${ }^{15}$.

Furthermore, a number of candidate genes have identified by genome-wide association studies that contribute to asthma. Recently, studies suggested that variation in genes encoding IL-33 and IL-1 receptor-like 1 (IL-1RL1) has an association with asthma. IL-1RL1 is a part of the IL-33 receptor complex ${ }^{16}$. IL-33 is a member in the IL-1 family of cytokines such as IL-1ג and IL-18, but IL-33 promotes Th2 cells, unlike other members which mostly create $\mathrm{TH} 1$ inflammation ${ }^{17}$. After epithelial cell injury, IL-33 releases as an alarm signal and activates other immune cells such as basophils, Th2 cells and mast cells, leading to the secretion of other cytokines like as IL5 and IL13 which have a major role in starting allergic inflammation in asthma ${ }^{18}$. A recent study significantly found higher levels of IL-33 and total IgE were detected in asthmatic patients compared with controls ${ }^{19}$.

Moreover, Interleukin-33 (IL-33) was connected to the progression of several allergic disorders such as atopic dermatitis (AD) and asthma and also assumed to participate in the acceleration of T-helper17 cell-mediated in mast 
cells of airway inflammation process ${ }^{20}$. Therefore, it is obvious from previous immunological studies that IL-33 play both as T-helper2 inducing cytokines and pro-inflammatory cytokine as IL-1 and IL-18 ${ }^{20}$. In 1987, Adam first stated that HCMV infection is associated with atherosclerosis: By significant detection of antibody in the case group more than in the control group ${ }^{21}$. Furthermore, HCMV IgG antibody levels are associated with ischemic heart disease (IHD) among organ transplant recipients compared to sero-negativity ${ }^{21}$. As atherosclerosis (AS) is an inflammatory disorder related to numerous risk factors with complex pathophysiology ${ }^{23}$. From various mechanisms associated atherosclerotic plaque, there was evidence propose that an allergic process plays a role in atherosclerosis pathogenesis $^{24,25}$.

A study detects a relation of CMV-DNA with a higher risk of atherosclerosis as detection of IgE with allergic immune responses, in patients with acute myocardial infarction or unstable angina pectoris; as double those in patients with stable angina pectoris or without coronary heart disease. Furthermore, CMV-DNA was present in 8 $(14.5 \%)$ of the cases and $2(4 \%)$ of the controls. (P $=0.03)^{26}$.

The interaction between allergy, atherosclerosis and IgE have gradually come to light. Evidence from in vitro experiments using animal models suggests that the connections between IgE and mast cells trigger the release of a diversity of substances in a direct or indirect way ${ }^{25,26}$. A study was detected CMV DNA in patients with fatal myocarditis and exposed the detection of CMV DNA in cardiomyocytes in the most samples comparing to the control subjects ${ }^{27}$. Another study was revealed patients with coronary artery disease (CAD) had higher serum IgE levels than those without CAD ( $p=0.003)$, so it proposed as Immunoglobulin E (IgE), play a significant role in allergic reactions, it can be involved in the atherosclerosis development ${ }^{28}$.

There was a previous controversy hypothesis of the interrelationship between allergies and cardiovascular diseases problems ${ }^{8}$. So, the recent study added to the old hypothesis; it is possible that disorders, with continuous inflammation course, reflected by high levels of proinflammatory cytokines or secretion disturbances that induced by some viral agents throughout old or recent reactivation of viral infection maybe contribute to the pathological process and encourage to induce these disorders as co-factors in the pathogenesis. This problem needs more studies. Hopefully, in the future, they will deliver valuable visions into preventing or treated one disorder in order to prevent the other, by targeting the viral infection or dealing with some of the pro-inflammatory cytokines.

Finally, evidence has suggested IL-33 as therapeutic and beneficial effects as antagonist target in allergic disorders such as asthma, Studies suggesting IL-33 a potential therapeutic target against allergies in murine models of allergic rhinitis, lower airway inflammation, and allergic contact dermatitis ${ }^{21}$.

\section{CONCLUSION}

The recent study has boundaries, but our outcomes had a statistically significant association in the pathogenesis of the two selected disorders with the studied serological markers, further exploration is needed to validate our recent outcomes. In addition, these finding proposed that interleukin-33 and IgE maybe dependently or independently play a role in the inflammatory process that leads to asthma or heart disorders. Finally, our recent results suggest, that CMV infection (or $\backslash$ and) recent reactivation may be related to asthma or heart disorders, (and \or) may contribute to the pathogenesis of them.

\section{ACKNOWLEDGMENTS}

None

\section{CONFLICTS OF INTEREST}

The authors declare that there are no conflicts of interest.

\section{AUTHORS' CONTRIBUTION}

All authors have made substantial, direct and intellectual contribution to the work and approved it for publication.

\section{FUNDING}

None. 


\section{DATA AVAILABILITY}

All datasets generated or analyzed during this study are included in the manuscript.

\section{ETHICS STATEMENT}

The current study was approved by the Centre of Ethical Committee

\section{REFERENCES}

1. ICTV. "Virus Taxonomy: 2014 Release". Retrieved 15 June 2015.

2. Gkrania-Klotsas E., Langenberg C., Sharp S.J., Luben R., Khaw K.T., \& Wareham N.J. Sero-positivity and higher immunoglobulin $\mathrm{G}$ antibody levels against cytomegalovirus are associated with mortality in the population-based European prospective investigation of cancer-Norfolk Cohort. Clinical infectious diseases, 2013, 56(10): 1421-1427.

3. Jahan M., Tabassum S., \& Islam M. Comparison of CMV pp65 antigen and IgM antibody detection for early recognition of CMV primary infection and reactivation. Mymensingh medical journal: MMJ, 2008, 17(1): 2831.

4. Simanek A.M., Dowd J.B., Pawelec G., Melzer D., Dutta A., \& Aiello A.E. Seropositivity to cyto-megalovirus, inflammation, all-cause and cardio-vascular diseaserelated mortality in the United States. PloS one, 2011, 6(2): e16103.

5. Muhsin Jasim Mohammed. Relationship Determination between Heart Diseases with Endometrial Adenocarcinoma and Ovarian Carcinoma by Evaluating the HPV16 IgG, IgM and p53 in Some IraqiFemale Patients. Iraqi Journal of Biotechnology, 2016, 15(2): 74-80.

6. Bansal A., \& Biswas D. Role of herpesviruses in coronary artery disease. Heart India, 2018, 6(3): 75.

7. Tan D.B., Amran F. S., Teo T. H., Price P., \& Moodley Y.P. Levels of CMV-reactive antibodies correlate with the induction of CD28 null T cells and systemic inflammation in chronic obstructive pulmonary disease (COPD). Cellular \& molecular immunology, 2016, 13(4): 551.

8. Bergmann K., \& Sypniewska G. Is there an association of allergy and cardiovascular disease?. Biochemia medica: Biochemia medica, 2011, 21(3): 210-218.

9. Muhsin Jasim Mohammed \& Abbas Sahira Hamdan. Evaluation of the possible role of HPV16, CMV and EBV in Cervical Carcinoma progression using In Situ Hybridization technique. Diyala Journal of Medicine, 2016, 11(1): 37-43.

10. Muhsin Jasim M. Study the possible role of CMV and EBV infections to initiate high blood pressure in some groups of hypertensive Iraqi patients. Diyala Journal For Pure Science, 2017, 13(1): 117-129.

11. Muhsin Jasim M. Study the possible Seropositivity connection of EBV, Rubella Virus \& CMV infection with four groups of autoimmune diseases in sample of Iraqi patients. Journal of Al-Nisour University College, 2017; 2(2).

12. Muhsin Jasim Mohammed; Abdul-Majeed B.A., \& Al-
Khalidi S. J. In situ hybridization approach for detection of epstein-barr virus \& human papillomavirus type 16 in a group of Iraqi women with cervical carcinoma. Al-taqani, 2014; 27(2): E22-E31.

13. Aihara M., Sugita Y., Takahashi S., Nagatani T., Arata S., Takeuchi K., \& Ikezawa Z. Anticonvulsant hypersensitivity syndrome associated with reactivation of cytomegalovirus. British Journal of Dermatology, 2001; 144(6): 1231-1234.

14. Kowalski M.L., Wardzynska A., Studzinska M., Pawelczyk M., Lesnikowski Z.J., \& Paradowska E. Cytomegalovirus DNA is highly prevalent in the blood of patients with asthma and is associated with age and asthma traits. Allergy, 2017; 72(12): 2035-2038.

15. Rogala B., \& Gl ck J. The role of interleukin-33 in rhinitis. Current allergy and asthma reports, 2013; 13(2): 196202.

16. Grotenboer N. S., Ketelaar M.E., Koppelman G. H., \& Nawijn M. C. Decoding asthma: translating genetic variation in IL33 and IL1RL1 into disease pathophysiology. Journal of Allergy and Clinical Immunology, 2013; 131(3): 856-865. e9.

17. Louten J., Rankin A.L., Li Y., Murphy E.E., Beaumont, M., Moon C., ... \& de Waal Malefyt, REndogenous IL-33 enhances Th2 cytokine production and T-cell responses during allergic airway inflammation. International immunology, 2011; 23(5): 307-315.

18. Saluja R., Ketelaar M.E., Hawro T., Church M.K., Maurer M., \& Nawijn M.C. The role of the IL-33/IL-1RL1 axis in mast cell and basophil activation in allergic disorders. Molecular Immunology, 2015; 63(1): 80-85.

19. Momen T., Ahanchian H., Reisi M., Shamsdin S. A., Shahsanai A., \& Keivanfar M.Comparison of interleukin-33 serum levels in asthmatic patients with a control group and relation with the severity of the disease. International journal of preventive medicine, 2017; 8.

20. Ding W., Zou G.L., Zhang W., Lai X.N., Chen H.W., \& Xiong L. XInterleukin-33: its emerging role in allergic diseases. Molecules, 2018; 23(7): 1665.

21. Adam E., Probtsfield J.L., Burek J., McCollum C.H., Melnick J.L., Petrie B.L., ... \& DeBakey M.E. High levels of cytomegalovirus antibody in patients requiring vascular surgery for atherosclerosis. The Lancet, 1987, 330(8554): 291-293.

22. Gkrania-Klotsas E., Langenberg C., Sharp S.J., Luben R., Khaw K.T. \& Wareham N.J. Higher immunoglobulin G antibody levels against cytomegalovirus are associated with incident ischemic heart disease in the populationbased EPIC-Norfolk cohort. The Journal of infectious diseases, 2012; 206(12): 1897-1903.

23. Libby P., Ridker P.M., \& Maseri A. Inflammation and atherosclerosis. Circulation, 2002; 105(9): 1135-1143.

24. Potaczek D.P. Links between allergy and cardiovascular or hemostatic system. International journal of cardiology, 2014; 170(3): 278-285.

25. Lippi G., Cervellin G., \& Sanchis-Gomar F. Immunoglobulin E (IgE) and ischemic heart disease. Which came first, the chicken or the egg?. Annals of medicine, 2014; 46(7): 456-463.

26. Heybar H., Alavi S. M., Nejad M.F., \& Latifi M. Cytomegalovirus infection and atherosclerosis in 
candidate of coronary artery bypass graft. Jundishapur journal of microbiology, 2015;, 8(3).

27. Palmeira M.M., Ribeiro H.Y.U., Lira Y.G., Neto F.O. M.J., da Silva Rodrigues I.A., da Paz L.N.F. \& Pinheiro M.D.C.N. Heart failure due to cytomega-lovirus myocarditis in immunocompetent young adults: a case report. BMC research notes, 2016; 9(1): 391.

28. Guo X., Yuan S., Liu Y., Zeng Y., Xie H., Liu Z., ... \& Shen Z. Serum IgE levels are associated with coronary artery disease severity. Atherosclerosis, 2016; 251: 355-360. 